\title{
Information and Communication Technologies (ICTs) and Autistic Spectrum Disorders (ASD)
}

\author{
http://dx.doi.org/10.3991/ijes.v4i1.5352 \\ Athanasios S. Drigas, and Jenny A. Vlachou \\ NCSR DEMOKRITOS, Institute of Informatics and Telecommunications, Net Media Lab, Athens, Greece
}

\begin{abstract}
The aim of this report is to provide systematic analysis of studies investigating ICT tools for children with Autistic Spectrum Disorders. They are categorized into ICT assessment tools and ICT intervention tools. The review outlines the origin of each tool, its functionality by describing certain technological features and how it attributes to this scientific field. On the one hand, there are many ICT tools that contribute in the diagnosis of ASD. On the other hand, ICT intervention tools play also an important role, trying to enhance both cognitive and social abilities of the ASD child. Through the review of these articles, we try to investigate how far they have come in meeting these targets.
\end{abstract}

Index Terms - assessment, ICT, intervention, special education, ASD, SEN, Asperger Syndrome, AS, CBI, ASC

\section{INTRODUCTION}

\section{A. Autistic Spectrum Disorder (ASD)}

Autism Spectrum Disorders (ASD) also known as Pervasive Development Disorders, include autistic disorder, Asperger Syndrome and Pervasive Development Disorder - Not otherwise Specified (PDD-NOS; American Psychiatric Association, 2000). The term "Spectrum" refers to the wide range of impairment or disability that children with ADS have. Social interaction and social communication are core areas of impairment even for students with high functioning autistic syndromes, such as Asperger (AS). Students with AS may be proficient in academic and work tasks, but often fail in school or jobs because of social demands.

\section{B. Information and Communication Technology (ICT)}

The presence of information and communication technologies (ICT) in society is an evident reality and an area of special reflection and continuous evolution that has expanded in recent years due to the speed of technological advances and their impact on the educational world [1]. Most institutions have embodied this technology into schools, as an attempt to improve their teaching perspective through the ICT equipment. In fact the presence of ICT equipment in schools has increased exponentially over the years [2].

In the case of students with special educational needs, technology is a critical input because the capabilities of these media allow these students to access tasks that would otherwise remain beyond their reach. New technologies configured as a powerful teaching tool could provide the solution to some special educational needs of students. [3].

Computer is popular and preferable among people with ASD because it is predictable, consistent, free from social demands and specific in focus of attention [4]. Therefore computer-based applications are considered to be useful tools for therapeutic and educational purposes. For example, applications have been developed to train social skills [5]. They can work on their own pace and level of understanding. Lessons can be repeated many times. They can maintain interest and motivation because the applications can provide personalized feedback [6].

On the below mentioned categories, ICT tools will be analyzed regarding their efficacy as assessment and intervention tools towards ASD people.

\section{ICT TOOLS}

\section{A. ICT assessment tools}

Jasni Dolah et al. (2012) reported a study that investigates the levels of autism symptoms among adults, that are undergraduate students of the Sains Malaysia University, of average intelligence, using the Autism Spectrum Quotient (ASQ). ASQ involves a questionnaire of 50 questions of Likert Scales, published by Simon BaronCohen in 2001 and an online survey. The responders are required to select one option at a time. The closed box answers lie between a "Definite Agree" to a "Definite Disagree" scale. The estimations are carried out through ANOVA, using SPSS, statistic software. The study was being conducted due to a tremendous increase on the number of Autism cases worldwide and on Malaysia itself. The questionnaire includes questions relating to the efficacy of this instrument towards identification of ASD, awareness of how alternative methods can help in learning ASD and if these instruments are the proper ones for recognizing ASD. The instrument's objectives head to determine what is the percentage of age/race group that have low and high levels of ASD, the feedback analysis of ASQ and the suggestions of alternative methods in ASD identification. These results, based on the scoring point set by ASQ, showed that most responders had an average score of autistic symptoms, in general. The score between gender, showed a distinction over the female, suffering from ASD in Malaysia. The race score, showed that Malays are more effected than Chinese and other tribes. In conclusion, it's the society that should be more educated on the matter of ASD and not treat these symptoms as a taboo. Development of suitable material is also crucial for the treatment of ASD [7].

Noel Kok Hwee Chia et al. (2013) present on chapter 8 of their paper "Learning Activity System Design for Autistic Children Using Virtual Pink Dolphins," the Virtual Pink Dolphin Project, a VR application that can improve the prognosis of ASD children, as well as develop a protocol for improving their quality of daily living. In this pro- 
ject, a learning game with VR dolphins makes children follow visual instructions to control the dolphins with certain gestures. Dolphins are supposed to perform certain antics in 3 levels of difficulty and will be guided by the children to achieve that. Children will get rewards after successfully completing each level. Beginners are provided with a tutorial. The project is hosted in the Institute for Media Innovation in Singapore. The Institute is interested in further research for an enhanced VR-based treatment that teaches communication, social interaction and daily living skills to ASD children with ASD [8].

In 2014, Salvatore Maria Anzalone et al. conducted a research which compared, during a Joined Attention (JA), how Autism Spectrum Disorders ( ASD) and children with Typical Development (TD) interact with a robot in a 4-D environment. A small humanoid robot, Nao, was used in conjunction with a perception system based on a RGB$D$ sensor that attributed to capture movements and information regarding the children's overall response. Specifically, ASD cases were diagnosed through a real time system which collected the data of the experiment and an offline system analyzed the data through certain algorithms. Constrained Data Models (CLM) and Generalized Adaptive View-based Appearance Model (GAVAM) algorithms estimated postures, such as depth image, head pose, face and skeleton track of each child, that were then analyzed into a child's possible problematic behavior of gazing and posture. When Nao was altered with a human being, both categories (ASD \& TD), especially ASD children responded better. Thus, Nao robot could be referred as an assessment tool for ASD cases recognition. On the other hand, Nao can be used as a machine learning robot in an attempt to compose personalized therapeutic activities, with specified techniques to regain attention. The experiment was held in Pitie Salpetriere Hospital Ethics Committee in Paris among 32 children, half of which were ASD sufferers and the other half were TD students from Paris. The outcome was that, in both children categories, the results depended on the interaction partner and are not to be seriously evaluated since they were validated only on a small group [9].

\section{B. ICT intervention tools}

In 2011, J.Lozano, J. Ballesta and S.Alcaraz Murcia introduced a project which claims to promote digital inclusion in the media to enable the integration of people who have difficulty in accessing technology. In their report, "Software for teaching emotions to students with autism spectrum disorder", an educational software, "Apren de con Zapo. Propuestas didacticas para el aprendizaje de competencias emotionales y sociales", is used to teach and assess the social and emotional skills of students with ASD. It provides a controlled environment through contact with the main character (clown Zapo), who the student gets along with, while carrying out the various tasks in the program. The results confirmed that such educational software can help students with ASD to perform tasks aimed at the understanding of emotional skills, promote their ability to work in pairs and interact with a peer. These facts were noticed by both teachers and families [10].

Weiqin Chen et al. (2012) presented their research on "Multitouch tabletop technology for people with autism spectrum disorder. A review of the literature". This postWIMP (Window, Icon, Menu and Pointer) technology provides touch screen, large physical space, multitouch and supports natural interactions without the need of the mouse pointer. Most important multitouch platforms are: Smartboard, Diamond Touch, Microsoft Surface and tabletops based on FTIR (Frustrated Total Interaction Reflection). Software that accompanies these devices are: Sides, Collaborative Puzzle Game (CPG), Raketeer, Join-inSuite, Trollskogen (The Troll Forest). The main advantage of such technologies is that they provide user communication and working together capabilities, that users find attractive. Final outcome is that there is still need on how to provide support among individuals with autism, their families and professionals who support them [11].

In 2010, Rung-Yu Tseng and Ellen Yi-Luen Do presented "Facial expression wonderland (FEW) - A novel design prototype of information and computer technology (ICT) for children with autism spectrum disorder (ASD)". The acronym "FEW" comes from Facial Expression Wonderland. The goal of the program is to train children with ASD in facial expression recognition through a game, since children find it amusing and concentrate better by playing. The game is divided into three levels, all accompanied by voice guidance, where they have to match pictures of facial expressions with ones of emotions. The effects of FEW are yet to be estimated and validated in the future [12].

In 2011, Sathiyaprakash Ramdoss et. al focused on the "Use of computer-based interventions to improve literacy skills in students with autism spectrum disorders". The review was based on 12 studies, for the use of CBI on improving literacy skills in ASD students. The various software packages used across studies outline that CBI is an intervention delivery approach and not an intervention in and of itself. Thus, the success relies on the effective teaching procedures of the software program, such as prompting and reinforcement. Alpha program, Baldi / Timo, Delta Messages and Teach Town are programs designed to deliver instruction. There was a difficulty in evaluating the grade of success in these interventions and this can be attributed to:

1. The small sample of participants

2. Participants' lack of prior skills and knowledge on computer use.

The reviewed studies emerged two relevant approaches:

1. Offer CBI only to those with a background knowledge on computers.

2. Efficiently instruct students on the specific hardware and software before beginning CBI in literacy.

Despite that the ability to use a computer is a worthy skill, it may not make a positive impact on literacy learning. Furthermore, it is known that in cases of Asperger Syndrome, the sufferers confront difficulties in identifying facial expressions, thus they may face similar difficulties with images. Nevertheless, there is an expressed concern that the use of CBI through ASD students may impede on their social skills and interactions. The possibility that inserting certain features, such as animated faces or multichannel feedback, on CBI will prove to be effective is awaited for research [13].

Karen Stendal et al. (2012) through "Virtual Words: A new opportunity for people with lifelong disability", investigated how people with lifelong disabilities such as ASD can develop social contact. It is encouraging that 
minimum skills are required to use a virtual world successfully. As long as there are no high support needs involved, anyone can enjoy social interaction with others regardless of their disabilities; it's in their preferences to make their disabilities known, since in this digital world each person can adopt the appearance of an able-bodied avatar. Indicatively, in Second Life, people with Asperger Syndrome can find people alike in an Island, called "Brigadoon", while people who use wheelchairs can socialize in a club called "Wheelies". Virtual Worlds is an intervention tool since it has been used to educate people with intellectual disability as well as to train them in social skills [16]. Yet it is questioned whether the skills learned through this process can be easily generated to the real world by all [14].

David Lima and Thais Castro (2012) presented "Music Spectrum, a V.R. Music environment for Children with Autism", based on Gold's research, which states that music therapy can intervene and promote a positive change [18]. The Development process of the Music Spectrum Model was divided into 4 phases:
i. Requirements
ii. Project
iii. Implementation
iv. Evaluation

Currently, the application is implemented in iOs from Apple Inc. in order to be broadly tested for gameplay interaction, before implementing it on an open-source platform. The input can be controlled by the user. Four screens have been designed, all in 2-D for initial testing.

i. A user can log in or register. Also, language preferences are available at the same screen.

ii. Social Profile: Edit profile, View Friends, Group and Activity options are available.

iii. Violin presentation

iv. Violin playing, from an imaginary level to composing a real song.

The purpose is to awaken the individual with ASD in a more dynamic interaction from exploring an instrument till participating in some social group [15].

Lesley Abbot et al. (2004) introduced a research "The global classroom: advancing cultural awareness in special schools through collaborative work using ICT, European Journal of Special Needs Education" referring to a crossnational collaboration of Northern Ireland and Republic of Ireland mainstream and special education schools through ICT. Schools worked in pairs; they chose a joint subject to study. Communication was being held by:

1. Asynchronous computer conferencing that provided:

1.1. Text based conferences

1.2. Digital publishing of educational resources

2. Videoconferences that provided an on-line contact between pupils.

The goals of the research were to estimate:

I. The development of cultural awareness through ICT conferencing and videoconferencing.

II. The progress on pupils' literacy and ICT skills through conferencing.
III. The progress on pupils' oral and communication skills through videoconferencing.

The results, especially in special education needs (SEN) children were that the prior mentioned goals were achieved, plus an increase in self-esteem, motivation for academic aspirations and high poise in public speaking through videoconference was noticed [17].

In 2011, Florence D. DiGennaro Reed et al. conducted a research on "applications of technology to teach social skills to children with autism". With an overview on literacy search procedures, six inclusionary criteria were applied to the articles. These were: (1) Length in pages should not overcome four and the publication should be made in a peer review journal. (2) Sound experimental technology had to be used in order to compare the effects of treatment. (3) A social skill that had to be addressed was the focus of the study. (4) The implementation of a technology-based intervention to address the social skill deficit was required. (5) Participants had to be 18 years old or younger and be diagnosed of autism or an consanguineous disorder. (6)The article had to be written in English. With an overview on the coding procedures, the review focused on the following variables: (a) The technology used to deliver the intervention, could be a computer program, an ipod or smartphone, a virtual reality environment, a video/DVD, a tactile prompt, an audio script, a robot or other technology. (b) Topography of targeted social skills included 9 categories, referring to conversational skills. Finally, the results supported that technology can be integrated into interventions for social skills deficits [19].

In 2013, Stefano Piana et al. presented " a set of full body movement features for emotion recognition to help children affected by Autism Spectrum Condition", a work which is part of the EUFP7 ICT 3-years Project ASCInclusion, that aims at developing ICT solutions to assist children affected by ASD. Specifically, it focuses on the development of serious games to children to understand and express emotions, by processing facial expressions, voice, full-body movement and gesture. This framework first monitors ASC children while they interact with others or play a serious game and evaluates their ability to express and understand emotions. Then, it improves the children's cognition of emotions by using interactive multimodal feedback. Interpretation of body movements is crucial since certain gestures express feelings, such as fear, joy, anger or surprise. Interpretation of other factors, such as velocity and directness of movements are also being examined. These movement data are recorded by using professional grade optical motion capture systems and video cameras. The data are then refined through Dictionary Learning and Sparse Coding techniques. The classification task is carried out using Support Coding Techniques. Once refined, the development emotion analysis algorithms are applied on low-cost RGB-D sensors (e.g. kinect). Conclusions on ASD children are yet to come, since the framework has only been tested on adult actors [20].

In 2011, Wendy Keay-Bright presented a report "Is simplicity the key to engagement for children on the autism spectrum?", which claimed that the more simple an application is, the less anxiety an ASD child is likely to feel while using it. The main aim was to arouse curiosity 
and interaction. The author recommended two software programs: Reac Tickles and Pah! Reac Tickles offers shapes, marks and colored patterns that children can draw easily through any input mode (mouse, keyboard, microphone, touchscreen), enabling children's creativity. Pah! is a voice-operating game that reacts to changes in volume, measured against background noise. The findings stated that Pah! game offers less creativity to the user, than ReacTickles. The report outlined the necessity to educate technology through simple software tools, so that a SEN child will use it without the intervention of a tutor [21].

In 2008, Wendy E.Keay-Bright conducted a paper that reports the findings of "Tangible Technologies as Interactive Play Spaces for Children with Learning Difficulties: The Reactive Colours Project in The International Journal of Technology, Knowledge and Society", which are (a) the development of customizable sensory software, ReacTickles and (b) the impact of embodied user interfaces on learning for children with autism. ReacTickles is being studied as far as its tangible technology input devices are concerned. The ReacTickles keyboard promoted ASD children's confidence as they enjoyed exploration with it alone and ReacTickles Interactive Whiteboard helped them socialize as they were inviting the participation of others to draw shapes, morphs, colors with the touch of their fingers [22].

S.V. Cobb et al. (2010) did some research over the COSPATIAL project through their report "An integrative approach for designing collaborative technologies for social competence training in children with autism spectrum conditions." The above mentioned project is investigating two collaborative technologies, collaborative virtual environments (CVEs) and Shared Active Surfaces (SASs), as appropriate media to enhance learning of social competence skills for children with and without autism. COSPATIAL works alone with the Principals of Cognitive Behavior Therapy (CBT). CBT offers a multimodal framework that takes into account cognition and behavior for guiding intervention efforts. That is why education technology counts several factors such as Personalization, User Centered Design (UCD) and Understanding Autism. To conclude, COSPATIAL offers facilitation on social competence towards children with autistic spectrum conditions but the main challenge is whether our chosen technologies can develop social competence as required by the CBT [23].

Zeljka Car et al. (2012) presented a report "Introducing Session on ICT-Based Alternative and Augmentative Communication". Alternative and augmentative communication (AAC) is based on the use of graphic and textual symbols to represent certain objects, actions or concepts aiming at the improvement of speech, literacy, learning, employment and quality of life for people with complex communication needs. ICT-based AAC services enable symbol-based, human-to-human and human-to-machine communication in a computer and networking environment. Persons with severe SEN, such as those with intellectual and communication impairments, find ICT-based AAC services crucial for their lives, since they suffer from isolation and the only way to socialize is through ICT. Finally, parents' participation in the research and development of ICT-based AAC services is wanted. Parents point out that alternative communication should be based on big imaging without distracting details, secondary motives should be avoided; a clear and simple font like
Arial is advisable and vivid colors like red, that is the quickest to reach the brain, can be used so as to emphasize words [24].

Peter Francis et al. (2009) promoted a study "Towards co-design with users who have autism spectrum disorders", that stands for the idea that people with ASD can participate in the designing process of Digital Assistive Technology (DAT), as long as these parties are ones with high functioning autism (e.g. Asperger Syndrome) and codesign is conducted under conventional ways. Amongst DAT, some are highlighted: Boardmaker and PECS, the visual assistant and Jogger, PDA-based products of Able Link Technologies are tools that basically provide prompting. Moreover, projects as the "Mobility for all", the" Isaac" and "Virtual Environment Systems" help ASD people develop social skills in ways they prefer and have already disclosed [25].

In 2012, Margarita Lucas da Silva described an application named Troc@s that was developed to make fully customizable tools available to children with ASD. The application has the advantage of being a communicative tool to the autistic children. As a result, it can be used not only for educational purposes but also for leisure. It contains images, videos, audio and stories. From the tutor's objective this tool is designed so as the tutor can customize the contents easily. It uses web technologies. Moreover, the tutor can adjust the application according to each child, have full control over the software and intervene at all levels, with some HTML and CSS editing. The evaluation is still yet to be completed and will be addressed towards the tutor's satisfaction, as well as the children's [26] \& [27].

Theresa Doyle and Immaculada Arnedillo-Sanchez (2010) described a framework for carers (teachers and parents) to help them create personalized social stories for ASD children, using multimedia context. The aim was to reveal the "hidden code" (the do's and dont's) of everyday behavior to children. This specifically involved six thematic areas: Around the house, personal care, at school, social skills, going places and things to avoid. The stories being used were adapted to suit each individual. They included step by step instructions, role play, all emphasized mostly in visual structure (colorful images, animation, sounds) and less in text, since they cannot stay focused on it. This framework helped to heighten the awareness of carers to the needs of the children and this seemed to improve the response from the latter. Further training of carers, who encounter difficulties, would enable them to use the framework to its full potential [28].

In 2012, J. Mintz conducted a study on the importance of specific factors, such as credibility and Kairos, which are some of the principals for the design of persuasive systems, according to Fogg [30], for designing HANDS. HANDS is a project based on a smartphone application that ameliorates improper social and life behavior of ASD children, along with their teachers' and parents' contribution. Teachers intervene in their diary functioning through a software, installed in a web based toolkit, providing an efficient computer - human interaction that is no other than teacher - child interaction, helping them on crucial moments of their everyday life. Parents, on the other side, provide teachers with information feedback of their child's preferences and specificities and are likely to intervene like teachers do in the future, as long as they have the technology skill to do so. 
Social skills management may include prompts to help them in remembering tasks to do, or text messages to advise them in emotional situations that are difficult to handle. Life skills interventions involve money management, time management, using the public transportation etc.

This research was applied on male ADS students from 4 schools among UK, Denmark, Sweden and Hungary with positive results, considering the use of smartphone/PDA technology tools in teachers' mediation towards behavioral issues of children. There is definitely a potential for persuasive mobile applications to facilitate the social and life skills of ASD children in the near future [29].

In 2009 Kostandinidis Evdokimos et al. reported the work carried out in the Lab of Medical Informatics at the Aristotle University of Thessaloniki in Greece, amongst recent trends in the education of children with special needs. These educational approaches include Interactive Environments/ Software Platforms (with the use of animated pictures or videos), Robotic Systems, Virtual Environments, Avatars, the TEACCH Method (Treatment and Education of Autistic and related Communication Handicapped children) and Special Input Devices, all set to rehabilitate autistic children through attractive education. The platform works on virtual and semi-virtual environments. The first one includes modules that require image identification, listing pictures according to time sequence and practice on emotional awareness. The latter includes modules that are a part of our everyday life, such as objects, activities, words, etc. The platform is enhanced with an avatar figure, speaking in the user's native language, that acts as an instructor. Moreover, the avatar expresses emotions according to situations and has the advance of a personalized platform in correspondence to his level and needs. The user is also guided by written text, makaton symbols and sounds. The results are promising, since latest research has shown that the more interactive an ICT tool is, the more intervention is being achieved in the child's disorder. Nevertheless, there is much need for improvement; technologies could extend their capabilities, especially to wearable sensors, which could provide a more accurate feedback for the autistic persons [31].

In 2010, L.Millen et al., stated " the development of educational collaborative virtual environments for children with autism" and how helpful that can be to them, especially when they are included in the design process. Two projects will be reviewed next: (1) AS Interactive was a project to explore the feasibility of using virtual environments for rehearsal and practice of social skills in young adults with Asperger's Syndrome. A user centered design process was applied, in which, different stake holders informed different stages of design and development of VE. A variety of methods to obtain user input to the review of VE content, layout, interface and functionality were explored. (2) COSPATIAL was the second project exploring the use of innovative technologies for supporting the development of social competence for ASD children, as well as their typically developing peers. Teachers were also included in the design process, like in the AS Interactive, though pupils weren't currently involved. It utilized collaborative virtual environments (CVE's) rather than the single user VE's developed in the AS Interactive Project. In conclusion, such technologies that include children users in the design process are fairly promising. It still remains a challenge though how exactly can this be achieved, since there is a lack of research in it [32].

\section{DISCUSSION}

Some authors state that there may be some deficits on ICT in the intervention area but this is due to the fact that autism is an especially difficult disorder to treat because of its triad of impairments (i.e. Stereotyped behavior, communication and social interaction), it's co-morbid subtypes (e.g. Timothy's Syndrome and Rett's Syndrome) and varying degrees of severity that range from mild to profound. Some advanced technologies are improving the treatment for children with ASD. Special effort is being made in order to include the newest media, like mobile and social media, in the training and intervention of ASD. Exploitation of the new trends of ICTs, like artificial intelligence and serious games, is also considered important since children remain focused while using them. Software that offers personalization features is improving the intervention process towards autistic children. Greater results can be accomplished if ADS persons, especially high functioning ones, or their parents take part in the designing process of such technologies, providing information about the ASD person's preferences. It is bare truth that the number of autistic cases has increased tremendously the latest years, thus it is a necessity that the society should be awakened and not treat this matter as a taboo.

\section{CONCLUSION}

To conclude, it is crucial to develop the suitable learning technologies for the ASD persons' needs. ICT can provide major assistance towards serious cases of ASD, regarding the improvement on their life-social and occupational capabilities. Adapting ICT for SEN cases remains a challenge, yet we still need to understand how to take full advantage of this technology to provide the best possible support for individuals with autism, their families and professionals who support them.

\section{REFERENCES}

[1] Selwyn N. \& Gouseti A. (2009). School \& Web 2.0: A Critical Perspective. Educatio Siglo XXI, 27(2); 147-165. URL: https://digitum.um.es/xmlui/bitstream/10201/27053/1/School and Web 2.0. A critical perspective.pdf

[2] María Rocío Díaz Gómez, José Ignacio Aguaded Gómez. (2010). La institucionalización de la te - leformación en las universidades andaluzas. RUSC, 7(1); 1-11. URL: http://dialnet.unirioja.es/serv let/articulo?codigo $=3119033$

[3] Alba, C. (1998). Perspectivas de futuro en la utilización de las nue - vas tecnologías de la información y comunicación en la for mación co mo respuesta a la diversidad. Píxel-Bit, 10. URL: www.sav. us.es/ - pixelbit/pixelbit/articulos/n10/n10art/art103.htm

[4] Murray D.( 1997) Autism and information technology: therapy with computers. In: Powell S, Jordan R, editors. Autism and learning: A guide to good practice. London: David Fulton Publishers.

[5] Bernard-Opitz V, Sriram N, Nakhoda-Sapuan S.(2001) Enhancing social problem solving in children with autism and normal children through computer-assisted instruction. Journal of Autism and $\begin{array}{lll}\text { Developmental } & \text { Disorders. } & 31(4): 377-384 . \quad \text { URL: }\end{array}$ http://link.springer.com/article/10.1023/A:1010660502130, http://dx.doi.org/10.1023/A:1010660502130

[6] Moore D, McGrath P, Thorpe J.(2000) Computer aided learning for people with autism a framework for research and development. Innovations in Education and Teaching 37:218 228.URL: http://www.tandfonline.com/doi/abs/10.1080/13558000050138452 , http://dx.doi.org/10.1080/13558000050138452 
[7] Jasni Dolah, Wan Ahmad Jaafar Wan Yahaya, Toh Seong Chong, A. Rahman Mohamed (2012) Identifying Autism Symptoms using Autism Spectrum Quotient (ASQ): A survey amongst Universiti Sains Malaysia Students. URL: http://www.sciencedirect.com/ science/article/pii/S1877042812050495, http://dx.doi.org/10.1016/ j.sbspro.2012.11.072

[8] Noel Kok Hwee Chia, Yiyu Cai, Norman Kiak Nam Kee, Nadia Thalmann, Bianyue Yang, Jianmin Zheng and Daniel Thalmann (2013) Learning Activity System Design for Autistic Children Using Virtual Pink Dolphins, Chapter 8. URL: http://link.springer.com/chapter/10.1007\%2F978-981-4021-90$6 \_8$

[9] Salvatore Maria Anzalone, Elodie Tilmont, Sofiane Boucenna, Jean Xavier, Anne-Lise Jouen, Nicolas Bodeau, Koushik Maharatna, Mohamed Chetouani, David Cohen (2014) How children with autism spectrum disorder behave and explore the 4dimensional (spatial 3D + time) environment during a joint attention induction task with a robot, Research in Autism Spectrum Disorders, pages 814-826. URL: http://www.sciencedirect.com/ science/article/pii/S1750946714000452, http://dx.doi.org/10.1016/ j.rasd.2014.03.002

[10] J. Lozano, J. Ballesta, S. Alcaraz, Murcia (2011) Software for Teaching Emotions to Students with Autism Spectrum Disorder. URL: http://eprints.rclis.org/18102/1/en139-148.pdf

[11] Weiqin Chen (2012) Multitouch Tabletop Technology for People with Autism. URL: http://ac.els-cdn.com/S1877050912007855/1s2.0-S1877050912007855-main.pdf? tid=30db9248-8a16-11e5843b-00000aacb360\&acdnat $=1447426541 \quad 20710 \mathrm{a} 50 \mathrm{~b} 42150 \mathrm{a} 6$ $031190 \mathrm{~b} 13 \mathrm{a} 647 \mathrm{~d} 1 \mathrm{e}$

[12] Rung-Yu Tseng, Ellen Yi-Luen Do (2010), Facial Expression Wonderland (FEW) - A Novel Design Prototype of Information and Computer Technology (ICT) for Children with Autism Spectrum Disorder (ASD). URL: http://dl.acm.org/citation.cfm? id $=1883064$

[13] Sathiyaprakash Ramdoss, Austin Mulloy, Russell Lang, Mark O’Reilly, Jeff Sigafoos, Giulio Lancioni, Robert Didden, Farah El Zein (2011) Use of computer-based interventions to improve literacy skills in students with autism spectrum disorders: A systematic review. URL: http://www.sciencedirect.com/science/article/pii/ 1750946711000675

[14] Karen Stendal, Susan Balandin, Judith Molka-Danielsen (2011)Virtual worlds: A new opportunity for people with lifelong disability? , Journal of Intellectual and Developmental Disability , pages 80-83. URL: http://www.tandfonline.com/doi/full/10.3109/ 13668250.2011.526597\#.VHNNN9KsWSp, http://dx.doi.org/10. 3109/13668250.2011.526597

[15] David Lima, Thais Castro (2012), Music Spectrum: a Music Immersion Virtual Environment for Children with Autism. URL: http://www.sciencedirect.com/science/article/pii/S1877050912007 752, http://dx.doi.org/10.1016/j.procs.2012.10.013

[16] Parsons S., Leonard A., Mitchell P. (2006). Virtual environments for social skills training: Comments from two adolescents with autistic spectrum disorder. URL: http://www.sciencedirect.com/sci ence/article/pii/S0360131504001460, http://dx.doi.org/10.1016/ j.compedu.2004.10.003

[17] Lesley Abbott, Roger Austin, Aidan Mulkeen, Nigel Metcalfe (2004) The global classroom: advancing cultural awareness in special schools through collaborative work using ICT, European Journal of Special Needs Education. pages 225-240. URL: http://www.tandfonline.com/doi/abs/10.1080/08856250410001678 504 - .VFzR5jSDmSo, http://dx.doi.org/10.1080/08856250410001 $\underline{678504}$

[18] Gold C., Wigram T., Elefant C. (2006). Music therapy for autistic spectrum disorder. The Coherence Database of Systematic Reviews. URL: http://onlinelibrary.wiley.com/doi/10.1002/14651 858.CD004381.pub2/abstract;jsessionid=EFC1D0F0426A25508F BF34BA3D538BD4.f02t02? userIsAuthenticated =false\&deniedAc cessCustomisedMessage $=, \quad$ http://dx.doi.org/10.1002/14651858. CD004381.pub2

[19] Florence D. DiGennaro Reed, Sarah R. Hyman, Jason M. Hirst (2011) Applications of technology to teach social skills to children with autism. URL: http://www.sciencedirect.com/science/article/ pii/S1750946711000286
[20] Stefano Piana, Alessandra Staglianò, Antonio Camurr, Francesca Odone (2013) A set of Full-Body Movement Features for Emotion Recognition to Help Children affected by Autism Spectrum Condition. URL: http://www.fdg2013.org/program/workshops/papers/ IDGEI2013/idgei2013_4.pdf

[21] Wendy Keay-Bright, Imogen Howarth (2011) Is simplicity the key to engagement for children on the autism spectrum? URL: http://link.springer.com/article/10.1007/s00779-011-0381-5

[22] Keay-Bright, Wendy E., (2008) Tangible Technologies as Interactive Play Spaces for Children with Learning Difficulties: The Reactive Colours Project in The International Journal of Technology, Knowledge and Society Vol.4. URL: https://repository.cardiffmet. ac.uk/dspace/handle/10369/773

[23] S V Cobb, L Millen, T Glover, S Parsons, S Garib-Penna, P L Weiss, E Gal, N Bauminger, S Eden, M Zancanaro, L Giusti (2010) An integrative approach for designing collaborative technologies for social competence training in children with autism spectrum conditions. URL: http://www.icdvrat.org/2010/papers/ ICDVRAT2010 SP N02 Cobb etal.pdf

[24] Zeljka Car, Dinka Vukovic, Nadica Bjelcic, Goran Karas, Velimir Karas (2012), Introducing Session on ICT-Based Alternative and Augmentative Communication. URL: http://link.springer.com/ chapter/10.1007\%2F978-3-642-30947-2_25

[25] Peter Francis, Sandrine Balbo, Lucy Firth (2009) Towards codesign with users who have autism spectrum disorders.URL: http://link.springer.com/article/10.1007/s10209-008-0143-y

[26] Margarida Lucas da Silva, Carla Simões, Daniel Gonçalves, Tiago Guerreiro, Hugo Silva,Fernanda Botelho (2011) TROC@S: Communication Skills Development in Children with Autism Spectrum Disorders via ICT. URL: http://link.springer.com/ chapter/10.1007/978-3-642-23768-3 103

[27] Margarida Lucas da Silvaa, Daniel Gonçalvesb, Tiago Guerreirob, Hugo Silva A Web-Based Application to Address Individual Interests of Children with Autism Spectrum Disorders. URL: http://ac.els-cdn.com/S187705091200765X/1-s2.0-S18770509120 0765X-main.pdf? tid=5d9ace46-8e05-11e5-be1d-00000aacb35f\& acdnat $=1447859120 \quad 5 \mathrm{f} 67 \mathrm{a} 6 \mathrm{~b} 9 \mathrm{cb} 4149 \mathrm{~b} 92 \mathrm{ae} 66 \mathrm{a} 2 \mathrm{e} 60 \mathrm{~d} 819 \mathrm{fe}$

[28] Theresa Doyle, Inmaculada Arnedillo-Sánchez (2010) Using multimedia to reveal the hidden code of everyday behavior to children with autistic spectrum disorders (ASDs). URL: http://www.sciencedirect.com/science/article/pii/S0360131510002 $37 \mathrm{X}$

[29] Joseph Mintz, Corinne Branch, Caty March, Stephen Lerman (2011) Key factors mediating the use of a mobile technology tool designed to develop social and life skills in children with Autistic Spectrum Disorders. URL: http://www.sciencedirect.com/science/ article/pii/S0360131511001710

[30] Fogg B.J. (1997) Charismatic Computers: Creating more likable and persuasive interactive technologies by leveraging principles from social psychology. URL: http://virtual.inesc.pt/rct/ show.php?id=73

[31] Konstantinidis, Evdokimos I., Luneski, Andrej, Frantzidis, Christos A., Nikolaidou, Maria, Hitoglou-Antoniadou, Magda and Bamidis, Panagiotis D. (2009) Information and communication technologies (ICT) for enhanced education of children with autism spectrum disorders. The Journal on Information Technology in Healthcare, 7 (5). pp. 284-292. URL: http://eprints.whiterose. ac.uk/11044/

[32] L. Millen, R. Edlin-White, S. Cobb (2010) The Development of Educational Collaborative Virtual Environments for Children with Autism. URL: http://geniiz.com/wp-content/uploads/2012/01 1.pdf

[33] Whitby, Peggy J. Schaefer; Ogilvie, Christine; Mancil, G. Richmond (2012) A framework for teaching social skills to students with Asperger Syndrome in the General Educational Classroom. URL: http://web.b.ebscohost.com/abstract?direct=true\&profile= ehost\&scope $=$ site \&authtype $=$ crawler\&jrnl $=11889136 \&$ AN $=7926$ 8609\&h=Kak19DbzOLFkAfQRwwD0EmgcdjwHoBBzYsxAHSK YxEk8KLJhcYRWt41T0i\%2fpnCPgEi4NuccaQ8PyiL\%2fNV ZSzLA $==\& \mathrm{crl}=\mathrm{c} \&$ resultNs $=$ AdminWebAuth\&resultLocal $=$

[34] Michael Connor (2000) Asperger Syndrome (Autistic Spectrum Disorder) and the Self-Reports of Comprehensive School Students. URL: http://www.tandfonline.com/doi/abs/10.1080/71366 $\underline{6079}$ 


\section{AUTHORS}

Athanasios Drigas is a Senior Researcher at N.C.S.R Demokritos. He is the Coordinator of Telecoms Lab and founder of Net Media Lab since 1996. From 1985 to 1999 he was the Operational manager of the Greek Academic network. He has been the Coordinator of Several International Projects, in the fields of ICTs, and e-services (elearning, e-psychology, e-government, e-inclusion, eculture etc). He has published more than 200 articles, 7 books, 25 educational CD-ROMs and several patents. He has been a member of several International committees for the design and coordination of Network and ICT activities and of international conferences and journals. (e-mail: dr@iit.demokritos.gr).

Jenny Vlachou (MA in Teaching Methodology of Computer Science) is a Special Education ICT Teaching Professional. (e-mail: jvlachou@gmail.com).

Submitted 11 December 2015. Published as resubmitted by the authors 28 February 2016. 